\title{
A COMPARATIVE STUDY OF DIFFERENT METHODS OF TREATMENT FOR INFERIOR TURBINATE HYPERTROPHY
}

\author{
B. Annapoorna Rao ${ }^{1}$, N. Veeraswamy², T.V.S.S.N. Leela Prasad ${ }^{3}$, B. Sudheer Chandra ${ }^{4}$, S. Surya Prakasa Rao ${ }^{5}$
}

${ }^{1}$ Assistant Professor, Department of ENT, Andhra Medical College, Visakhapatnam.

${ }^{2}$ Assistant Professor, Department of ENT, Andhra Medical College, Visakhapatnam.

${ }_{3}^{3}$ Assistant Professor, Department of ENT, Andhra Medical College, Visakhapatnam.

4Junior Resident, Department of ENT, Andhra Medical College, Visakhapatnam.

5Professor, Department of ENT, Andhra Medical College, Visakhapatnam.

\section{ABSTRACT}

\section{BACKGROUND}

The inferior turbinate plays a pivotal role in normal nasal physiology. The inferior turbinate hypertrophy can cause decreased nasal airflow and sensation of nasal obstruction. Many methods (Conservative and surgical) have been tried to deal with this hypertrophy, but the most ideal method is still to arrive. Conservative management is temporary and recurrence is common. About 13 types of surgical procedures have been described over the past century in correcting inferior turbinate hypertrophy.

\section{OBJECTIVES}

There are number of studies and original articles, which could not come to conclude a standard procedure. The present study is conducted in a tertiary care ENT Institute. We have selected 30 patients for each procedure and a total number of 90 patients were operated and followed up for 6 months.

\section{RESULTS}

At the end of 6 months, the nasal obstruction symptoms are relieved in 1 . Turbinoplasty procedure $96.7 \%$, followed by 2 . Partial turbinate resection 83.5\%, least in 3 . Submucous diathermy 50\%. Conclusion: Among the three techniques, turbinoplasty proved to be better in terms of functional outcome (Only 2 out of 30 had nasal block) with relatively less complications like bleeding and crusting than the other two procedures.

\section{KEYWORDS}

Inferior Turbinate Hypertrophy, Submucous Diathermy, Partial Turbinectomy, Turbinoplasty.

HOW TO CITE THIS ARTICLE: Rao BA, Veeraswamy N, Prasad TVSSNL, et al. A comparative study of different methods of treatment for inferior turbinate hypertrophy. J. Evolution Med. Dent. Sci. 2016;5(40):2442-2444, DOI: 10.14260/jemds/2016/569

\section{INTRODUCTION}

One of the major causes of chronic nasal airway obstruction is pathology of the inferior turbinate. ${ }^{1}$ However, there is no agreement on how to deal with this problem. Pharmacological therapy is generally the treatment of choice. In many cases intranasal topical steroids, antihistamines and decongestants often yield good results. Patients who do not respond will usually be treated by surgical reduction of the turbinate. ${ }^{2}$ Since the last quarter of the $19^{\text {th }}$ century, at least 13 different techniques have been introduced. Some of them have already been abandoned, whereas others are still in use or have been reintroduced. There is considerable controversy over the merits of the various techniques. ${ }^{3}$ Some authors consider turbinectomy as an appropriate method, while others condemn it as too aggressive and irreversibly destructive. Another controversial technique is LASER treatment. Although numerous authors have recently advocated this modality, many rhinologists disapprove of it, as LASER destroys the mucosa and permanently impairs its functioning. 4

Financial or Other, Competing Interest: None.

Submission 08-02-2016, Peer Review 26-03-2016,

Acceptance 01-04-2016, Published 18-05-2016.

Corresponding Author:

Dr. S. Surya Prakasa Rao,

50-27-15/1,

Seethammadara, $N E$,

Visakhapatnam-530013.

E-mail: drssprao@gmail.com

DOI: $10.14260 /$ jemds $/ 2016 / 569$

\section{The Function of the Turbinates}

The inferior turbinates serve several important functions. They contribute to inspiratory resistance, which is necessary for normal breathing. The greater the nasal resistance, the greater the negative intrathoracic pressure needed for inspiration. Greater negative pressure in turn enhances pulmonary ventilation and venous backflow to the lungs and the heart. This is known as the 'Resistor function' of the turbinates. It is also a part of the valve area, which helps in changing the inspiratory lamellar airstream into a turbulent flow. 4,5 Turbulence in the outer layers of air increases the interaction between air and nasal mucosa. Humidification, warming up and cleansing of the air is thus enhanced. This role may be called the 'Diffuser function' of the inferior turbinates. Finally, they are essential to the nasal defence system (Mucociliary transport, humoral and cellular defence). All of these functions require a large amount of normally functioning mucosa, submucosa and turbinate parenchyma.6,7

\section{MATERIALS AND METHODS}

A total of 90 patients having inferior turbinate hypertrophy within age group of 15 to 60 years of both sex were selected for this study.

\section{Inclusion Criteria}

1. Inferior turbinate hypertrophy in deviated nasal septum.

2. Inferior turbinate hypertrophy in allergic rhinitis.

3. Inferior turbinate hypertrophy in chronic sinusitis. 


\section{Exclusion Criteria}

1. Inferior turbinate hypertrophy in nasal polyposis.

2. Inferior turbinate hypertrophy in benign tumours of nose.

3. Inferior turbinate hypertrophy with minimal atrophic changes.

They were divided into 3 equal groups of 30 and underwent one of the following three procedures. 1) Submucous diathermy, 2) Partial turbinectomy, 3) Turbinoplasty. They were followed up for a period of 3 weeks, 6 weeks, 3 months and 6 months.

\section{PROCEDURES}

Submucous diathermy: Intramucosal cautery is useful when attempting to induce involution of the mucosal glands within the submucosa without damaging the overlying ciliated mucosa. Needle tip cautery is used for this procedure.

After adequate anaesthesia, the needle is inserted into the submucosa of the turbinate along the inferior edge. The cautery is set for $15 \mathrm{~mA}$ and turned on for 30 to 45 seconds. The cautery is then removed and reinserted medially and superiorly a distance of 1 to $2 \mathrm{~cm}$ from the initial site. The cautery is repeated in this location and then moved superiorly again and repeated. Three locations along the medial surface are generally used. ${ }^{8}$

Partial turbinectomy: The clamp is placed over the anterior inferior two-thirds or less of the turbinate. The clamp is left there for 2 to 3 minutes and then released. The angled turbinate scissors are then used to cut along the crush line created by the clamp. After the turbinate is resected, suction cautery can be used to coagulate the raw edge. This will decrease the incidence of postoperative bleeding and obviate the need for the packing the nose. ${ }^{8}$

Turbinoplasty: After medialization of the turbinate, an L-shaped incision is made at its lateral-inferior margin. A mucosal flap is elevated and part of the turbinate bone and parenchyma is resected as required. The mucosal flap is then re-draped and fixed. (Modified Wormwald's techniquewithout microdebrider). This type of turbinoplasty allows reduction of the turbinate, while all mucosal functions are preserved and it has very low incidence of postoperative bleeding and crusting. 9,10

\section{OBSERVATION}

A total of 90 patients were included in the study, 30 in each group. Results were analysed by VAS (Visual Analogue Scale) and diagnostic nasal endoscopy.

\section{After 3 weeks,}

\begin{tabular}{|c|c|c|c|}
\hline Complications & $\begin{array}{c}\text { Submucous } \\
\text { Diathermy }\end{array}$ & $\begin{array}{c}\text { Partial } \\
\text { Turbinectomy }\end{array}$ & $\begin{array}{c}\text { Turbinopl } \\
\text { asty }\end{array}$ \\
\hline Haemorrhage & $0 / 30$ & $3 / 30$ & $0 / 30$ \\
\hline Crusting & $3 / 30$ & $20 / 30$ & $5 / 30$ \\
\hline Voice change & $0 / 30$ & $3 / 30$ & $0 / 30$ \\
\hline Persistent symp. & $15 / 30$ & $6 / 30$ & $4 / 30$ \\
\hline
\end{tabular}

After 6 weeks,

\begin{tabular}{|c|c|c|c|}
\hline Complications & $\begin{array}{c}\text { Submucous } \\
\text { Diathermy }\end{array}$ & $\begin{array}{c}\text { Partial } \\
\text { Turbinect } \\
\text { omy }\end{array}$ & $\begin{array}{c}\text { Turbinoplast } \\
\mathbf{y}\end{array}$ \\
\hline Haemorrhage & $0 / 30$ & $0 / 30$ & $0 / 30$ \\
\hline Crusting & $0 / 30$ & $3 / 30$ & $0 / 30$ \\
\hline Voice change & $0 / 30$ & $2 / 30$ & $0 / 30$ \\
\hline Persistent symp. & $15 / 30$ & $5 / 30$ & $3 / 30$ \\
\hline
\end{tabular}

After 6 months,

\begin{tabular}{|c|c|c|c|}
\hline Complications & $\begin{array}{c}\text { Submucous } \\
\text { Diathermy }\end{array}$ & $\begin{array}{c}\text { Partial } \\
\text { Turbinecto } \\
\text { my }\end{array}$ & $\begin{array}{c}\text { Turbinopla } \\
\text { sty }\end{array}$ \\
\hline Haemorrhage & $0 / 30$ & $0 / 30$ & $0 / 30$ \\
\hline Crusting & $0 / 30$ & $0 / 30$ & $0 / 30$ \\
\hline Voice change & $0 / 30$ & $2 / 30$ & $0 / 30$ \\
\hline Persistent symp. & $20 / 30$ & $3 / 30$ & $1 / 30$ \\
\hline
\end{tabular}

\section{DISCUSSION}

A total of 90 patients with inferior turbinate hypertrophy with deviated nasal septum, allergic rhinitis and chronic sinusitis were selected. They were divided into three groups, each group consists of 30 patients. They were treated by 1 st group by submucous diathermy, 2nd group by partial turbinectomy ( $50 \%$ of turbinate is reduced) and 3rd group by turbinoplasty (Modified Wormwald's technique).

\section{Among the Three Techniques}

1. In submucous diathermy, half of the patients were still having persistent nasal obstruction after 6 weeks. The effect of submucosal diathermy is often limited or temporary, so the procedure has to be repeated. The most common complications are delayed haemorrhage, prolonged nasal discharge and crusting. ${ }^{11}$

2. Partial resection of inferior turbinate is effective in successfully relieving symptoms like nasal block; however, bleeding is more common. Crusting is more common because of exposed inferior edge of inferior turbinate bone, which takes about 6 weeks to heal.12,13

3. Turbinoplasty allows reduction of the turbinate, while all mucosal functions are preserved and it has very low incidence of postoperative bleeding and crusting. Under endoscopic guidance, total visualization of operating field aids in optimal resection. Debulking of the turbinate while preserving the mucosa is the major advantage of this procedure, others being minimal blood loss and short operative time. ${ }^{14}$

\section{CONCLUSION}

In partial turbinectomy two patients had moderate haemorrhage, one patient had severe haemorrhage and required blood transfusion. More than half of the patients treated with submucous diathermy still have nasal obstruction. Hence, among the three techniques, turbinoplasty has proved to be better in terms of functional outcome (1/30), i.e. nasal block with relatively less complications like bleeding and crusting than the other two procedures. This study shows the treatment of choice for inferior turbinate hypertrophy is turbinoplasty of Modified Wormwald's technique.

\section{REFERENCES}

1. Jackson LE, Koch RJ. Controversies in the management of inferior turbinate hypertrophy: a comprehensive review. Plast Reconstr Surg 1999;103(1):300-12.

2. Mabry RL. Surgery of the inferior turbinate. How much and when? otolaryngol head neck surgery 1984;92:5716.

3. Butler J. The work of breathing through the nose. Clin Sci 1960;19:55-62.

4. Haight JS, Cole P. The site and function of the nasal valve. Laryngoscope 1983;93(1):49-55. 
5. Fradis M, Malatskey S, Magamsa I, et al. Effect of submucosal diathermy in chronic nasal obstruction due to turbinate enlargement. Am J Otolaryngol 2002;23(6):332-6.

6. Spector M. Partial resection of inferior turbinates. Ear Nose Throat J 1982;61:28-32.

7. Schmelzer B, Katz S, Vidts G. Long-term efficacy of oursurgical approach to turbinate hypertrophy. Am J Rhinol 1999;13(5):357-61.

8. Padgham N, Vaughan-Jones R. Cadaver studies of the anatomy of arterial supply to the inferior turbinates. J R Soc Med 1991;84(12):728-30.

9. Passali D, Lauriello M, Anselmi M, et al. Treatment of hypertrophy of the inferior turbinate: long-term results in 382 patients randomly assigned to therapy. Ann Otol Rhinol Laryngol 1999;108(6):569-75.
10. Williams HO, Fisher EW, Golding-Wood DG. Two-stage turbinectomy: sequestration of the inferior turbinate following submucosal diathermy. J Laryngol Otol 1991;105(1):14-6.

11. Courtis EH, Goldwyn RM, O'Brien JJ. Resection of obstructing inferior nasal turbinates. Plast Reconstr Surg 1978;62(2):249-57.

12. Elwany Samy, Harrison Robert. Inferior turbinectomy: comparison of four techniques. The journal of laryngology and otology 1990;104(3):206-9.

13. Martinez SA, Nissen AJ, Stock CR, et al. Nasal turbinate resection for relief of nasal obstruction. Laryngoscope 1983;93(7):871-5.

14. Percadoni J, Nicollas R, Dessi P, et al. Partial lower turbinectomy in children: indications, technique, results. Revue delaryngologie otology rhinology 1996;117(3):175-8. 